\title{
Automatic Bike as a Tool for Motor Development Programs for Children with Cerebral Palsy
}

\author{
${ }^{1}$ Risca Amani, ${ }^{2}$ Annisa, ${ }^{3}$ Yora Kurniawan, ${ }^{4}$ Dia Unnazif \\ 1,2,3Pendidikan Luar Biasa, Universitas Negeri Padang, Padang, Indonesia \\ ${ }^{4}$ Teknik Elektronika, Universitas Negeri Padang, Padang, Indonesia
}

\begin{abstract}
This article discusses the development and implementation of motor development tools to assist children with Cerebral Palsy. The failure to control motor function due to damage to the central nervous system has caused limbs stiffness resulting in the inability to carry out daily activities. The are some efforts to improve the limb stiffness for instance motor development activities to train muscles and joints. Utilizing a technology-based Automatic Bike can help implement the motor development program for children with Cerebral Palsy. The research includes a framework containing partners, problems, FGD, Automatic Bike, development, manuals and demonstration videos, FGD, information sharing, trials, results, and evaluation. Automatic Bike is a technology-based automatic bicycle that can be adjusted according to child's needs. This tool consists of pedals for upper and lower limbs which are driven by a motor. The implementation of the motor development program using Automatic Bike technology is carried out for four weeks frequently with a duration of 30 minutes a day. The continuous application of Automatic Bike can provide stimulus to both upper and lower limbs as the organs of movements, improving flex for joints and muscles stiffness along with increasing blood flow.
\end{abstract}

Keywords: Motor Development, Cerebral Palsy, Automatic Bike

\section{Background}

In the past few years, the number of children with special needs in Indonesia has increaesed, especially children with disabilities. The specialized agency for international public health or known as the World Health Organization (WHO) in 2003 reports the estimated prevalence of disabled children for about $7-10 \%$ of the total population of Indonesia (Pamilih, 2014). Some of these defects either congenital or after birth.

There are time periods in which major developmental milestones are resached. In children with characteristic brain disorders, some problems might prevent children from following the child's growth and development process. One of the disorders due to brain damage is called Cerebral Palsy.

Cerebral Palsy or static encephalopaty is a non-progressive damage caused by injuries to the brain during the prenatal, perinatal and postural periods. This disorder 
affects the inability to control motor function and movement due to damage to the central nervous system. In other words, it results in stiff muscles which make movement difficult (Andreani \& Kuswanto, 2019).

Cerebral Palsy refers to brain dysfunction disorders that are directly related to muscles, joints and bones. This disorder affects human movement system, especially in muscles and joints that experience stiffness. According to (Hernandez et al., 2012) children with Cerebral Palsy have muscle weakness, less range of motion and poor control of movement. Therefore, physical activity becomes limited which has an impact on the overall ability to move on daily basis or also called as Activity of Daily Living (ADL).

Cerebral Palsy is a disorder that affects the development of motor function which makes it difficult to do physical activity (Ye et al., 2012). According to Anggraeny et al., (2019) individuals with Cerebral Palsy have limited, monotonous movement and origin of motion. If the child makes a wrong move, then he will follow the wrong movement. Resulting in joint stiffness. Individuals with Cerebral Palsy also experience limitations in mobility and if the muscles are not moved for a long time it will result in decreased muscle function which affects the disruption of daily activities.

In general, Cerebral Palsy is divided into five, namely, spastic, athetoid, ataxia, floppy and mixed. Spastic is characterized by the shape of the muscles that are stiff. Meanwhile, athetoid is notable for uncontrolled movements. Then there is ataxic celebral palsy which is characterized by uncontrolled movement and constant shaking. On the other hands, floppy occurs when a child who has weak or even no muscle tone at all causing those with this CP only being able to lie down. The last type of CP is called mixture as a combination of some types, for example, between spastic and athetoid.

In spastic diplegia Cerebral Palsy, also known as paraplegia, the stiffness occurs in both upper and lower limbs. As a result, CP children cannot carry out daily activities independently. Therefore, secial training is needed to prevent stiffness getting worsen (Yatna \& Hastuti, 2016). Furthermore, children with Cerebral Palsy have decreased amount of motor control in both legs resulting the dependency to walk with mobility aids. There is higher stiffness found in children with Cerebral Palsy. This often causes the legs to pull together, turn inward and cross at the knees (Hernandez et al., 2013).

One particular training to promote the muscle function is by doing exercises to improve motor development. These exercises aim to change, improve and form motion patterns that are close to normal, so that the movements can be executed accordingly to the normal function. Motor development is a series of coaching and training activities that are planned and programmed for individuals with muscle, joint and bone disorders to promote the normal function.

Essentially, the training is meant to provide physiotherapist services to individuals with Cerebral Palsy (CP) intended to improve their ability to move in daily 
activities. In other words, individuals with CP are expected to develop the skills and abilities in carrying out daily activities in terms of mobility, helping themselves, and minimizing dependence on assistance from others, hence the individual can live independently.

The implementation of movement development training in special school (SLB) is usually applied through adapted physical education learning which has not been carried out optimally yet, or even some schools have not implemented it at all. The lack of teacher knowledge and understanding, limited tools, the pain and discomfort experienced by children while carrying out the program hinder the optimal implementation of this training. At the same time, parents want to provide maximum training by carrying out a therapy program, but are constrained by large therapy costs.

Based on these problems, utilizing the technology such as Automatic Bike will help the program to be effective and efficient. Automatic Bike is driven by a motor with automatic pedal speed that can be controlled (Annisa et al., 2019). Thus, the movement of the child's feet and hands follows the rotation of the pedals that are moved by the motor.

To optimize hand and foot movement exercises, CP children can apply a stationary bicycle to connect hand and foot movements (Pratiwi \& Indrojarwo, 2016). This is in line with Exergames, which is a video game that requires physical activity for children with Cerebral Palsy to play while exercising and having fun. This Exergames became known as the RacerBike, which is a device designed to resemble a bicycle to encourage children to be more active as the design has been adapted to the needs of children with Cerebral Palsy (Ye et al., 2012).

The exercises for foot and hand movement would be set at a low speed first. Then, the speed is increased gradually according to the child's improvement. In the application of Automatic Bike, the speed can be controlled from the motor that moves the foot and hand pedals. The number of rotations in each minute can be calculated and viewed on the Automatic Bike monitor.

Through the use of Automatic Bike technology, it can minimize pain in children while doing the training. The long-term use of the Automatic Bike can also help to flex the stiff joints, improve blood flow and stimulate the brain to the organs of movement of the feet and hands. In conclusion, Automatic Bike is an effective device to promote motor development in children with Cerebral Palsy.

\section{Automatic Bike for Children with Cerebral Palsy}

Motor development program is a set of activity including exercises and training to change, improve and form motion patterns that are close to normal, so that the movements can be executed accordingly to the normal function. Basically, the motor development program aims to provide physiotherapist services to individuals with 
Cerebral Palsy, hence independent improvement can be achieved. While doing this program, the therapists are expected to use more energy to assist children. Due to the therapists' physical condition, the training session might be not conducted maximally over a long period of time. Moreover, this training relies heavily on physical strength to flex, change, repair and shape the movement patterns of individual Cerebral Palsy.

The application of a technological tool can provide solutions to several problems found in the school environment. Adaptation of technology can provide implementation programs for children with Cerebral Palsy. The application of the technology provided is the Automatic Bike which is an automatic bicycle and is able to provide a stimulus to the hands and legs.

\subsection{Framework}

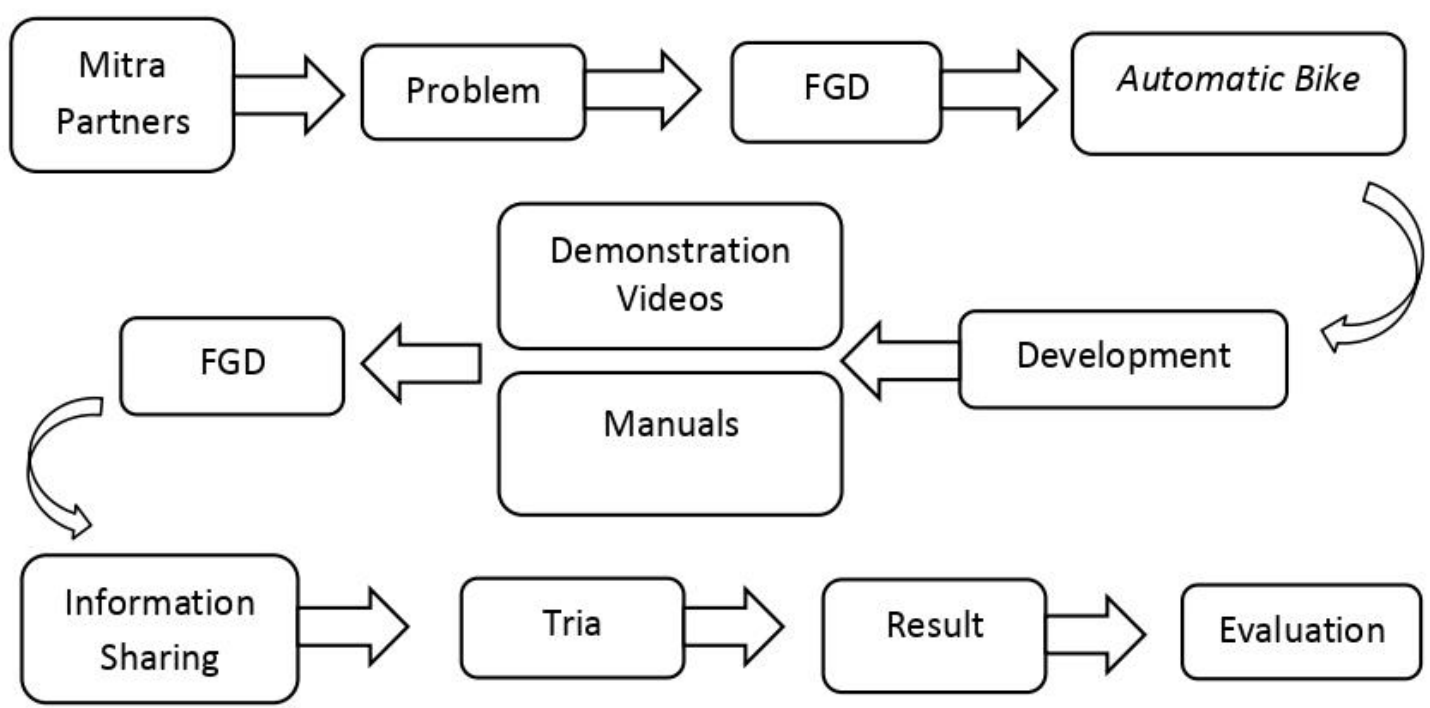

1. Mitra Partners

Starting with observations on partners to determine research subjects.

2. Problem

After finding the research subject, a problem is found that becomes an obstacle by the subject.

3. FGD

There is a Forum Discussion related to problems experienced by the subject followed by looking for solutions to these problems. The discussions are not only conducted by researchers but also simultaneously with partners.

4. Automatic Bike

Technology-based bicycles offer solutions to problems experienced by partners which also can used as a solution given to the subject.

5. Development 
Design development of a pre-designed Automatic Bike. This development is carried out based on the results of the evaluation of pre-existing designs. The results of the evaluation show that the user or partner also needs movement assistance not only for the lower limbs but also for the upper limbs so that the development of designs for automatic pedals on the upper limbs is produced.

6. Demonstration videos and manuals

The output is in the form of a manual to assist partners carrying out the implementation of the motor development program including animation videos as demonstration to use the Automatic Bike.

7. FGD

Forum discussion related to book and video on the implementation of the motor development program using Automatic Bike. A discussion held with partners is meant to explain the motor development program using technology.

8. Information Sharing

Information exchange regarding Automatic Bike with partners is to give a better understanding on the purpose of technology in motor development activities, so that it is easier to optimize activities and reduce possible problems experienced by the subject.

9. Trial

The Automatic Bike is tested after the development based on the previous designs is carried out in order to find solutions for the effectiveness.

10. Result

The trial brings a better result of the implementation of this Automatic Bike which is expected to improve joint and muscle stiffness experienced by Cerebral Palsy children.

11. Evaluation

Assessment of the implementation of the Automatic Bike as motor development tool which is presented as a solution for Cerebral Palsy children who experience stiffness in their limbs and hands.

\subsection{Implementation of Automatic Bike}

The motor development program using Automatic Bike technology is implemented by continuously training and exercise with a duration of 30 minutes a day. The following program of motor development using Automatic Bike technology for children with Cerebral Palsy, namely;

1. First week 
a. During the first week, the child is assisted by two assistants during the activities.

b. Children are carried when they get off the wheelchair.

c. Two assistants carry the child to ride the Automatic Bike.

d. CP children's upper and lower limbs are moved slowly by a motor which is planted

2. Second week

a. The child with CP is still assisted by two assistants during process.

b. The child is assisted when he wants to get off the wheelchair.

c. Two companions help the child on the Automatic Bike.

d. CP children's upper and lower limbs are moved slowly by a motor which is planted in Automatic Bike.

3. Third week

a. In the third week the child is assisted by only one assistant during process.

b. The child is supported by one person.

c. The child is assisted to get on the Automatic Bike

d. CP children's upper and lower limbs are moved slowly by a motor which is planted in Automatic Bike

4. Fourth week

a. The child is assisted by only one assistant during process.

b. The child is encouraged to walk towards the Automatic Bike while being assisted.

c. The child gets on the Automatic Bike with the assistance.

d. CP children's upper and lower limbs are moved slowly by a motor which is planted in Automatic

\subsection{Discussion}

Program The motor development program is a solution offered as a stimulus to improve limbs stiffness. The motor development program is adapted from one of Special School (SLB) programs regarding the needs of Celebral Palsy children which is followed by reliable educators who have full understanding of this program. However, surveys conducted proves that some special schools could not execute this program well likewise the optimum implementation of this program. Some factors that hinder the not optimum performance of this program, especially Special Schools in Padang, are the lack of media implementation, educators' lack of knowledge regarding this motor development program, the preference of doing therapy which requires a large amount of money, and school's policy that only focuses on the academic due to request of parents or from the school itself.

In facilitating the process of building motion in individual Cerebral Palsy and following the development of industry 4.0, some obstacles faced by teachers can be anticipated with technology. Automatic Bike is an automatic bicycle that is used to train 
human motor system. It can be utilized as the right technology to solve the problems that occur at Rumah Gadang Cerebral Palsy. This technology can help improve movement to be more efficient and effective without reducing the essence of motor development itself, as well as providing comfort to Automatic Bike users.

The use of Automatic Bike makes it very easy for motor development experts and parents when doing the exercises that require extra energy. In other words, Automatic Bike can decrease pain and discomfort experienced by children while doing exercises, at the same time it is more convenient for the experts who assist motor development exercises. Therefore, this activity can improve the motor system of Cerebral Palsy children to make it function properly.

Based on research and trial results conducted by Annisa et al. (2019), this previous study has succeeded in producing a motor development tool which is more convenient for teachers to implement motor development program.

According to Rimmer and Rowland (2008), to help improve physical health in individuals with Cerebral Palsy, physical activity is needed such as regular cycling which is coordinated and balance training, so that their physical condition becomes even better. This is also supported by Blumenstein et al. (2014) who states that adjusting bicycle based on user needs can provide opportunity disabled individuals especially quadriplegic.

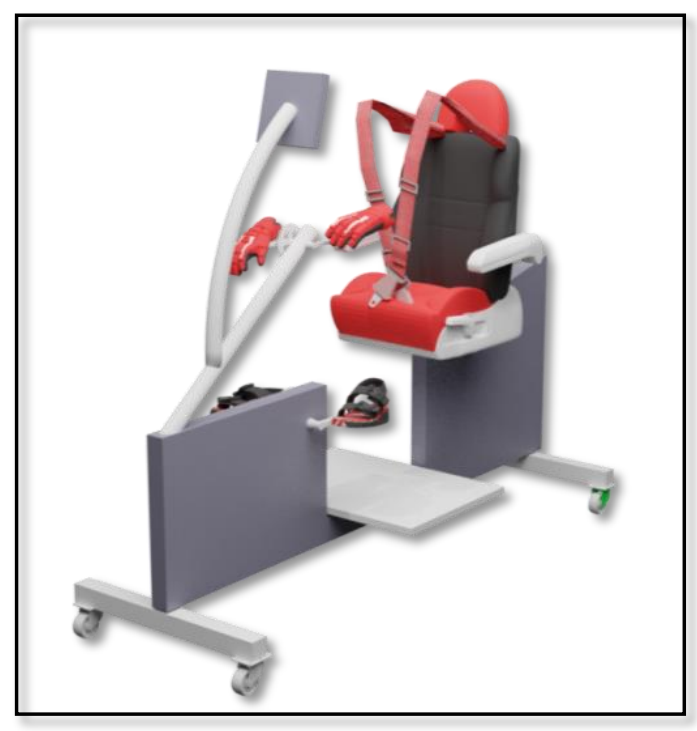

Figure 1. Automatic Bike

Automatic Bike is an automatic bicycle that is used to assist motor development program which utilizes technology for children with Cerebral Palsy. The use of Automatic Bike provides more convenient exercises for experts and parents who assist the CP children while doing motor development exercises that usually require extra energy. 
The design of the Automatic Bike is adapted to the condition of the Cerebral Palsy child so that it becomes effective and efficient to assist motor development program. The pedals are driven by a motor that rotates automatically, then the child can follow the rotation slowly. The pedal speed must be recorded during process to be evaluated, so that the impact of using the Automatic Bike can be tracked for the effectiveness of this program.

In addition, Blumenstein et al. (2014) states that pedaling can improve muscles during cycling. Bicycles with motorized adjustments with automatic pedals are designed with based on individual needs with adjusted motion. Furthermore, the speed of pedal rotation can be adjusted. The result is an automatic and customized bike which can provide a better spatial orientation for individuals with movement disorders.

However, the previous Automatic Bike design was only meant for the lower limbs. After further discussion regarding Automatic Bike, there was an upgrade design found. The improvement is pedaling for upper limbs and a cushion in the middle of the chair which helps to maintain the user's seated position. On the hand pedals, there is a glove to hold the child's hands while holding the pedal. Therefore, the hands would not come off easily as the gloves stick to the pedals. Both upper and lower pedals are driven by one motor.

Automatic Bike has components and functions which can be seen below:

a. Battery

The battery in the tomato bike is used to store electrical energy in the form of chemical energy, which will be used to supply electricity to the switch system, speed control system, Arduino R3, 16×2 lcd and other electrical components.

b. Switch

The function of the switch is to disconnect or connect the Tomato bike circuit to turn on or turn off the electrical circuit.

c. PWM Module

The PWM module functions to regulate the speed of the dc motor, the greater the given duty cycle value, it will affect the speed of the motor rotation. If the duty cylce value is small, the motor will move slowly.

d. Voltage Regulator

Serves to reduce the voltage from 12 to 9 volts using ic 7809 .

e. Switch NC 1

Serves to activate the hand pedal rotation

f. NC switch 2

Serves to activate the foot pedal rotation 
g. DC electric motor 1

DC Electric Motor 1 functions to convert electrical energy into kinetic energy or motion to rotate the hand pedal.

h. DC electric motor 2

The DC 2 Electric Motor functions to convert electrical energy into kinetic energy or motion to rotate the hand pedal.

i. Arduino UNO 1

Serves to store and run the stopwatch program

j. IR sensor module

Infrared (IR) detector or infrared sensor is an electronic component that can identify white light to determine the number of revolutions in a DC motor.

k. I2C MODULE

Inter Integrated Circuit or often called $12 \mathrm{C}$ is a two-way serial communication standard using two specially designed channels for sending and receiving data. The I2C system consists of SCL (Serial Clock) and SDA (Serial Data) channels that carry data information between the $\mathrm{I} 2 \mathrm{C}$ and the controller.

I. LCD $12 \times 6$

LCD (Liquid Cristal Display) functions as a data display for the number of laps and stopwatches in the form, letters and numbers.

m. Push Button 1

To reset / return to the initial display of the tool

n. Push Button 2

Activates the stopwatch function

o. Push Button 3

Serves to activate the monitor function of the number of pedal rotations.

p. Arduino uno 2

Stores and runs the program to monitor the number of pedal revolutions.

q. Potentiometer

Potentiometer (POT) is one type of resistor whose resistance value can be adjusted to adjust the light intensity on a $16 \times 2$ lcd.

The following steps explain the use of Automatic Bike, namely;

1. Put the CP child on the chair, then fasten the seat belt to maintain the user's sitting position. 
2. Adjust the distance between the user and the pedals by adjusting the position of the chair forwards and backwards.

3. Place the foot on the lower pedals which has been equipped with a strap.

4. Place the hands on the upper pedals that have been equipped with gloves to remain their position as the pedal rotating.

5. Press the ON button on the Control Box to turn on the motor.

6. Press the START button to start pedal rotation.

7. To adjust the rotational speed, turn the potentiometer clockwise and vice versa to reduce the speed.

8. Press the stop button to rest.

9. The number of laps will be recorded in the monitor, and the stopwatch will stop.

10. Press the RESET button to use it over.

11. Press the OFF button to turn off Automatic Bike.

12. Children with cerebral palsy can get off the Automatic Bike.

To facilitate the implementation, manuals and videos of Automatic Bike have been made. In this manual, detailed items in the Automatic Bike are explained along with the functions of each of these items. The utilization of the Automatic Bike is explained in details. Moreover, a video is provided to demonstrate the application of automatic Bike for children with Celebral Palsy

Both manual and videos are discussed again for improvement. This discussion was done with partners; therefore the appropriate design can be used for children with Cerebral Palsy. Then, information sharing is carried out with partners which is starting from the introduction of tool features, functions, ways of implementing and the impact of the Automatic Bike. Two-way communication is established, both from the partner to the researcher and vice versa.

Automatic Bike has been tested twice on children with Cerebral Palsy. This trial activity was accompanied by both parents and teachers. Thus, parents and teachers can witness the impact of using Automatic Bike on CP children.

Based on the results of these trials, Automatic Bike has a positive impact, especially on stiff joints. The trial was carried out for 30 minutes. In the first minutes of the experiment, the child was still adjusting to the pedal speed. In the first 20 minutes the child is able to follow the flow of the pedal eventually.

The implementation of motor development using Automatic Bike technology has a fruitful impact on limb stiffness. The next step will involve further trials to help evaluate the effectiveness of the Automatic Bike in improving the motor development program for children with Cerebral Palsy. 


\section{Conclusion}

Children with Cerebral Palsy have limited abilities to move due to motor problems, especially in the upper and lower limbs that experience stiffness. To minimize the severity of joint and muscle stiffness, a motor development training program is applied. During this program, some obstacles were found. The obstacles are the pain and discomfort experienced by the children while doing training and exercise, the requirement of extra energy, and inadequate media for the implementation of the motor development program.

Automatic Bike is a technology-based automatic bicycle to help motor development programs for children with Cerebral Palsy. The design of the automatic bike can be adjusted to the needs of the child to fulfill its effectiveness and efficiency in helping the process of applying this program. To assist the implementation process, manual and video have been provided. The continuous application of Automatic Bike can provide stimulus to both upper and lower limbs as the organs of movement, improving flex for joints and muscles stiffness along with increasing blood flow.

\section{Bibliography}

Andreani, I. M., \& Kuswanto, D. (2019). Pengembangan Desain Treadmill Sebagai Alat Latihan Berjalan Pada Cerebral Palsy Dengan Memanfaatkan Realitas Virtual. Jurnal Sains Dan Seni ITS, 8(1). https://doi.org/10.12962/j23373520.v8i1.41828

Anggraeny, D., Wahyudi, A., \& Budiyanto. (2019). Development of a Handbook to Improve Motor Coordination Among Students with Cerebral Palsy Type of Spastic Diplegia. Advance in Social Science, Education and Humanities Research, 388(Icse), 277-280.

Annisa, Aulianur, A., Luthfiyah, F., \& Mahdi, A. (2019). Tomat Bike (Automatic Bike) untuk Stimulasi pada Gangguan SistemGerak. Jurnal Penelitian Pendidikan Khusus, 7(2), 91-96.

Blumenstein, T., Zeitlmann, H., Alves-Pinto, A., Turova, V., \& Lampe, R. (2014). Optimization of electric bicycle for youths with disabilities. SpringerPlus, 3(1), 1-6. https://doi.org/10.1186/2193-1801-3-646

Hernandez, H. A., Graham, T. C. N., Fehlings, D., Switzer, L., Ye, Z., Bellay, Q., Hamza, M. A., Savery, C., \& Stach, T. (2012). Design of an Exergaming Station for Children with Cerebral Palsy. Conference on Human Factors in Computing Systems - Proceedings, 2619-2628. https://doi.org/10.1145/2207676.2208652

Hernandez, H. A., Ye, Z., Graham, T. C. N., Fehlings, D., \& Switzer, L. (2013). Designing Action-based Exergames for Children with Cerebral Palsy. Conference on Human Factors in Computing Systems - Proceedings, 1261-1270. https://doi.org/10.1145/2470654.2466164

Pamilih, C. Y. (2014). Penatalaksanaan neuro development treatment (ndt) pada kasus Cerebral Palsy spastic quadriplegi di yayasan sayap ibu cabang yogyakarta.

Pratiwi, P. C. P., \& Indrojarwo, T. (2016). Desain Mainan Anak Khusus Penderita Cerebral Palsy Dengan Konsep Menstimulus Koordinasi Gerak Anak. Jurnal Sains Dan Seni ITS, 5(2). 
Rimmer JA, Rowland JL. (2008) Physical activity for youth with disabilities: a critical need in underserver population. Developmental Neurorehabilitation 11(2):141-148.

Yatna, M. N., \& Hastuti, W. D. (2016). Pengaruh Senam Ritmik Tanpa Alat untuk Kelincahan Anak Cerebral Palsy Baseli. Jurnal Ortopedagogia, 2(1989), 1-4.

Ye, Z., Hernandez, H. A., Nicholas Graham, T. C., Fehlings, D., Switzer, L., Hamza, M. A., \& Schumann, I. (2012). Liberi and the racer bike: Exergaming technology for children with Cerebral Palsy. ASSETS'12 - Proceedings of the 14th International ACM SIGACCESS Conference on Computers and Accessibility, 225-226. https://doi.org/10.1145/2384916.2384965 